\title{
Correspondence
}

\section{Plasma von Willebrand factor in connective tissue disease}

SIR, Vascular endothelial cells synthesise von Willebrand factor (VWF), a high molecular weight protein that plays a part in the interaction of platelets with the subendothelium. ${ }^{12}$ The VWF is stored in the endothelial cells, and it can be released by a number of biological stimuli, including thrombin. ${ }^{3}$ If VWF release occurred in vivo as part of the endothelial response to damaging stimuli, a raised plasma level of VWF might indicate ongoing endothelial damage; this concept is supported by observations that plasma VWF is modestly raised (mean increase around two- to fourfold) in connective tissue disease associated with microvascular pathology. ${ }^{+8}$ The mechanisms of VWF release in these conditions have not been determined, and the relation between VWF levels and the course of the disease is not clear, but experimental studies have shown that VWF can be an acute phase reactant in animals. "If the increase in VWF in connective tissue disease reflected acute inflammatory episodes it should correlate with levels of a recognised acute phase reactant.

To investigate this we measured VWF by enzyme linked immunosorbent assay (ELISA), and $\mathrm{C}$ reactive protein by radial immunodiffusion, in plasma from 34 patients with scleroderma, 18 patients with systemic lupus erythematosus (SLE), 39 with rheumatoid arthritis (RA), and 37 normal controls. The mean level of VWF in the patients with scleroderma (1.42 (SD 0.66)) was significantly $(\mathrm{p}<0.03)$ greater than that of the control group $(1.13$ $(0 \cdot 41))$, though only six patients had levels above $2 \mathrm{IU} / \mathrm{ml}$. Levels in the groups with RA and SLE were also significantly raised, with mean values of $1.95(0.97)$ and $2.45(1.08)$ respectively (see Fig. 1). There was no correlation between levels of VWF and $\mathrm{C}$ reactive protein in the scleroderma and SLE groups, but positive correlation was found in the patients with RA (Spearman's rank correlation coefficient $0.39 ; p<0 \cdot 02$ ). Increase of VWF in the RA group was not associated with vasculitis.

Our results indicate that an increase in plasma VWF is common in SLE, RA, and, to a lesser extent, in scleroderma. This may reflect endothelial damage (in the

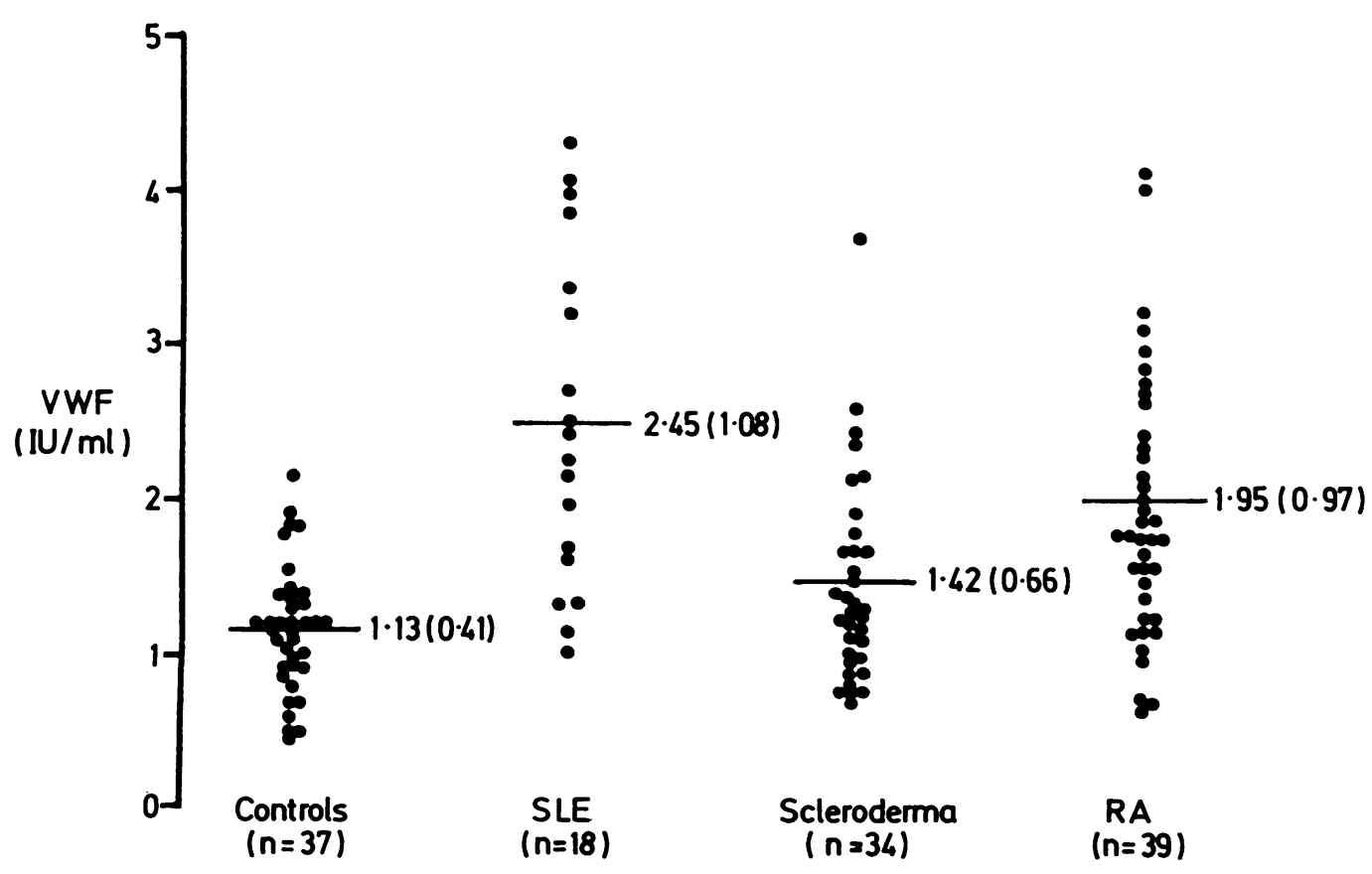

Fig. 1 Levels of VWF in the plasma of patients with connective tissue diseases. The horizontal bars show the mean for each group and the mean values (SD) are indicated. 
absence of another cause such as renal failure or liver disease), as has been previously suggested; however, it can also be associated with an acute phase reaction, and this should be borne in mind when interpreting the significance of VWF measurements.

MRC Clinical Research Centre. Harrow,

Middlesex

J L GORDON B E POTTINGER P WOO

Hôpital Henri Mondor. J ROSENBAUM Paris

C M BLACK

West Middlesex Hospital,

Isleworth.

Middlesex

\section{References}

1 Jaffe E A. Hoyer L W. Nachman R L. Synthesis of von Willebrand antihemophilic factor antigen by cultured human endothelial cells. Proc Natl Acad Sci USA 1973: 71: 1906-9.

2 Sakariassen K S. Bolhuis P A. Sixma J J. Human blood platelet adherence to artery subendothelium is mediated by factor VIIIvon Willebrand factor bound to the subendothelium. Nature 1979; 279: 636-8.

3 de Groot P G. Gonsalves M D. Loesberg C. van BuulWortelboer M F, van Aken W G, van Mourik J A. Thrombininduced release of von Willebrand factor from endothelial cells is mediated by phospholipid methylation. Prostacyclin synthesis is independent of phospholipid methylation. J Biol Chem 1984: 259: $13324-33$.

4 Angles-Cano E. Sultan Y. Clauvel J P. Predisposing factors to thrombosis in systemic lupus erythematosus. Possible relation to endothelial cell damagc. J Lab Clin Med 1979: 94: 312-23.

5 Kahaleh M B. Osborn I. LeRoy E C. Increased factor VIII/von Willebrand factor antigen and von Willcbrand factor activity in scleroderma and in Raynaud's phenomenon. Ann Intern Med 1981: 94: 482-4.

6 Nusinow S. Federici A B, Zimmerman T S. Curd J G. Increased von Willebrand factor antigen in the plasma of patients with vasculitis. Arthritis Rheum 1984: 27: 1405-10.

7 Lee P. Norman C S. Sukenik S. Alderdice C A. The clinical significance of coagulation abnormalitics in systemic sclerosis (scleroderma). J Rheumatol 1985; 12: 514-7.

8 Glueck H I. Kant K S. Weiss M A. Pollak V E. Miller M A. Coots $M$. Thrombosis in systemic lupus erythematosus. Relation to the presence of circulating anticoagulants. Arch Intern Med 1985: 145: 1389-95.

9 Kelly D. Tuddenham E G D. Summerfield J A. The effect of an acute phase reaction and BCG inoculation on factor VIII in the guinea pig. Thromb Res 1985; 40: 445-51.

\section{HLA antigens Dw4 and Dw14 in rheumatoid arthritis}

SIR. In a recent study in the Annals of Rheumatic Diseases
we assayed the differences in HLA system of 62 patients
with rheumatoid arthritis (RA) with various toxic effects of
gold salts and 23 RA controls without gold toxicity. 'The
findings included higher Dw 4 and Dw 14 and lower Dwl
incidences in the controls with classical rheumatoid
arthritis (RA) when compared with the gold toxicity
Table 1 Phenotypes of Dw4 or Dw14 positive patients, ore. patients positive for both

\begin{tabular}{|c|c|c|}
\hline & $\begin{array}{l}\text { Patients without } \\
\text { toxic effects } \\
(n=23)\end{array}$ & $\begin{array}{l}\text { Patients with } \\
\text { toxic effects } \\
(n=61)^{*}\end{array}$ \\
\hline $\begin{array}{l}\text { Dw4/x or }-\div \\
\text { Dw14/x or }- \\
\text { Dw4/w14 }\end{array}$ & $\begin{array}{l}6 \\
2 \\
5 \div\end{array}$ & $\begin{array}{r}13 \\
6 \\
0\end{array}$ \\
\hline
\end{tabular}

${ }^{*} \mathrm{D}$ typing missed in one patient.

$\div x$ means any other HLA-D specificity found.

$\doteqdot$ In DR typing only DR4 was found.

group, which was more heterogeneous as to the Americani Rheumatism Association criteria.?

Although we emphasised the differences in Dw4 and Dwl frequencies between the groups, the higher Dwle prevalence in the RA controls with classical RA wao disregarded in the discussion.

Recently, Dr Nepom and colleagues identified HLA $\overrightarrow{2}$ Dw4/w14 heterozygosity by allele specific oligonucleotide probes in five out of seven phenotypically DR4 homozy $\widehat{\Omega}$ gous (RA) patients who were found among 45 selected Caucasian RA patients with classical and seropositive disease. ${ }^{3}$ They proposed that their report was the first to describe high Dw14 in adult RA and suggested that the Dw14 allele may play an important part in susceptibility to RA.

We have now re-evaluated our series with regard to Dw4/Dw14 status. The table shows the phenotypes of Dw or Dw14 positive patients, or patients positive for both. in each group. The five Dw4/w14 heterozygotes in the group with classical RA without gold toxicity was significantl more than the expected number of 2.09 calculated from the phenotype frequencies $\left(\chi^{2}=4 \cdot(05, p<0 \cdot 05)\right.$. Instead. non of the patients with gold toxicity was Dw4/w14 heterod zygous. Our results obtained with cellular HLA-D typing thus agree with those of Dr Nepom and colleague concerning classical RA. Although the Dw4 and Dwl? genes both may be associated with disease susceptibilit (gene), their effect on the clinical picture of RA may be even stronger.

Department of Medicine.

Päivärinne Hospital.

Muhos, Finland

National Public

Health Institute.

Oulu. Finland

Department of

Medical Microbiology,

University of Oulu.

Oulu. Finland

\section{References}

I Hakala M. van Assendelft A $H$ W. Ilonen J. Jalava ST Tiilikainen A. Association of different HLA antigens wit 2 various toxic effects of gold salts in rheumatoid arthritis. $A \cap \mathbb{P}$ Rheum Dis 1986: 45: 177-82. 